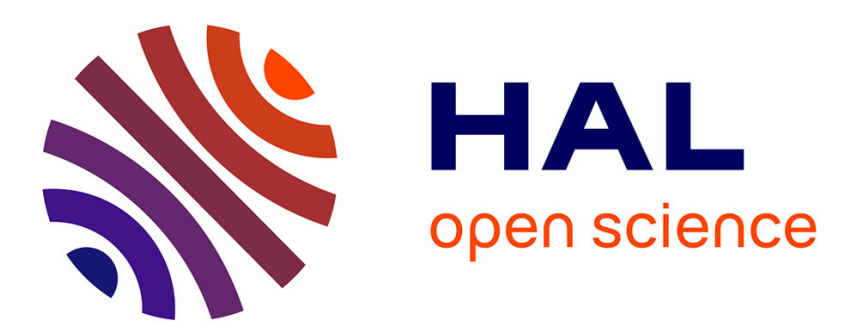

\title{
A single bunch selector for the next low $\beta$ continuous wave ion beam
}

G. Le Dem, M. Di Giacomo

\section{To cite this version:}

G. Le Dem, M. Di Giacomo. A single bunch selector for the next low $\beta$ continuous wave ion beam. 22nd Particle Accelerator Conference (PAC'07), Jun 2007, Albuquerque, United States. Joint Accelerator Conferences Website; IEEE, pp.158-160, 2007, 10.1109/PAC.2007.4440144 . in2p3-00169268

\section{HAL Id: in2p3-00169268 https://hal.in2p3.fr/in2p3-00169268}

Submitted on 3 Sep 2007

HAL is a multi-disciplinary open access archive for the deposit and dissemination of scientific research documents, whether they are published or not. The documents may come from teaching and research institutions in France or abroad, or from public or private research centers.
L'archive ouverte pluridisciplinaire HAL, est destinée au dépôt et à la diffusion de documents scientifiques de niveau recherche, publiés ou non, émanant des établissements d'enseignement et de recherche français ou étrangers, des laboratoires publics ou privés. 


\title{
A SINGLE BUNCH SELECTOR FOR THE NEXT LOW $\beta$ CONTINUOUS WAVE HEAVY ION BEAM *
}

\author{
G. Le Dem ${ }^{\#}$, M. Di Giacomo, GANIL, Caen, France
}

\section{Abstract}

The MEBT line of EURISOL heavy ion postaccelerator and the SPIRAL2 deuton/ion accelerator should transport a continuous wave $(\mathrm{cw})$ beam from a 88.05 MHz RFQ ( $\beta$ respectively 0.035 and 0.04 ) to a drift-tube linac. A high frequency chopper is being studied to select only 1 bunch over $\mathrm{N}$, respectively $10<\mathrm{N}$ and $100<\mathrm{N}$ as asked by the physicists. It requires pulse voltages up to $2.5 \mathrm{k} \mathrm{kV}$, rising in less than $6 \mathrm{~ns}$ at a repetition rate up to $8.8 \mathrm{MHz}$. These figures are at the border of what can be provided by the travelling wave fast choppers and the capacitive-type chopping technologies $[1,2,3,4]$. We have reviewed the current fast and slow chopping structures and their associated pulse generator [5]. Some preliminary RF simulations to adapt the present chopping devices to our requirements are presented. The main limitations of these technologies when applied to select one bunch in cw ion accelerators are also shown. Our first studies and results to solve the arising problems are discussed.

\section{INTRODUCTION}

The MEBT line of the EURISOL post-accelerator and the SPIRAL2 accelerator should transport continuous wave (cw) beams from a RFQ operating at the $88.05 \mathrm{MHz}$ frequency ( $\Delta t=11.36 \mathrm{~ns}$ ) to a drift tube linac (DTL). Both superconducting linacs are designed to have effective acceleration respectively for radioactive heavyions with a ratio $\mathrm{A} / \mathrm{q}$ from 4 to 8 , and either for deuton or heavy ions with a $\mathrm{A} / \mathrm{q}$ of 3 and 6 . The maximum beam current is respectively $1 \mu A$ and $5 \mathrm{~mA}$. The space charge effects are negligible in the EURISOL case. Many EURISOL experiments will require to chop the beam for periods from $10 \mathrm{~ns}$ to $1 \mathrm{~ms}$, which will be made by means of a high frequency chopper located in the MEBT line. Due to the physicist requirements the EURISOL and SPIRAL2 choppers should operate like a single bunch selector: one bunch over $\mathrm{N}$ should pass through the chopper output with the repetition rate resumed in table 1 .

After having adapted existing $50-\Omega$ travelling-wave (TW) electrodes to our cases, power constraints will be observed due to the $\mathrm{cw}$ mode of the beam and the physicist requirements. Two alternative ways might answer the requirements. We also decided to investigate another way to decrease power consumption: a $100-\Omega$ meander microstrip line. The length of the strip line can lead to attenuation and dispersion of the pulse signal along its propagation.
Table 1 : MEBT Chopper Specifications.

\begin{tabular}{|l|l|l|}
\hline & EURISOL & SPIRAL2 \\
\hline Max. bunch repetition rate & $1 / 10$ & $1 / 100$ \\
\hline Max. chopping pulse frequency & $8.8 \mathrm{MHz}$ & $880 \mathrm{kHz}$ \\
\hline$\beta$ & 0.035 & 0.04 \\
\hline Deflection section aperture & $20 \mathrm{~mm}$ & $24 \mathrm{~mm}$ \\
\hline Deflecting length & $450 \mathrm{~mm}$ & $650 \mathrm{~mm}$ \\
\hline High voltage $\left(\mathrm{V}_{0}\right)$ & $< \pm 2.5 \mathrm{kV}$ & $< \pm 2 \mathrm{kV}$ \\
\hline Rise / fall time $\left(\tau_{1}\right)$ & \multicolumn{2}{|c|}{$6 \mathrm{~ns}$} \\
\hline Pulse duration $\left(\tau_{\mathrm{ON}}\right)$ & $>98 \mathrm{~ns}$ \\
\hline
\end{tabular}
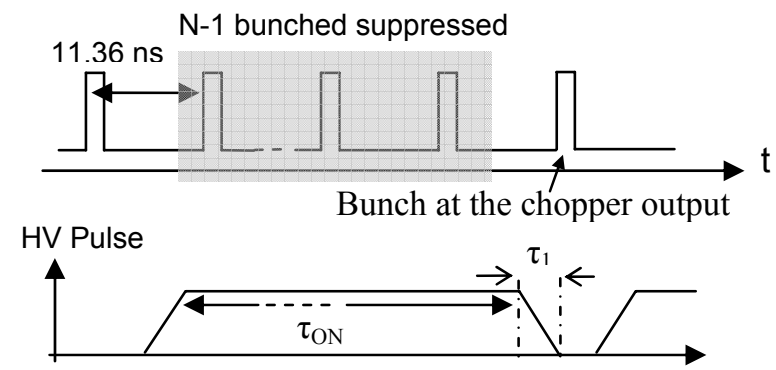

Figure 1: Beam structure and Chopping time structure.

\section{CW MODE CONSTRAINTS}

Fast rising times can be achieved either by travelling wave structures $[2,3,4]$ or by capacitive-type (C-type) chopper [6]. This scheme is used when rise time lower than $10 \mathrm{~ns}$ are searched. Chopper structure working at voltage level similar to those required for EURISOL are being studied for proton injectors foreseen to operate in the 300 to $400 \mathrm{MHz}$ frequency range and within rise/fall time of the deflecting pulse shorter than 2 ns. In preliminary studies the $50-\Omega$ SPL electrode was adapted to EURISOL and SPIRAL2 cases. For EURISOL and SPIRAL2, N-1 bunches over $\mathrm{N}$ should be suppressed where $\mathrm{N}$ exceeds respectively 10 and 100 . These values imply a duty cycle of the high voltage pulses always higher than $80 \%$. If a $50-\Omega$ SPL type electrode is used, the pulse generator has then to provide a average of RF power $>112 \mathrm{~kW}$, which is lost at $50-\Omega \mathrm{RF}$ matching load and at the equivalent resistance of the conductor strip. The power losses also exceed $6 \mathrm{~kW}$. Previous studies made by F. Caspers and T. Kroyer show that around $100 \mathrm{~W}$ of heat power can be dissipated for an operation temperature $100 \mathrm{~K}$ above the cooling temperature [1]. 


\section{ALTERNATIVE SOLUTIONS}

To decrease RF power and power losses, two alternative solutions seem to be good candidates: either a C-type structure like the RAL-ESS slow chopper [6] or an association of a TW electrode and a static B-filed steerer.

\section{Capacitive-type Chopper}

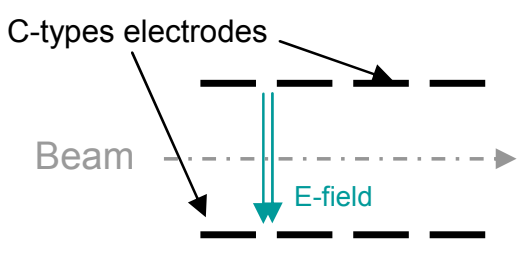

Figure 2: Scheme of a C-type chopper.

C-type choppers are typically based on capacitive electrode driven by a fast high voltage switch. To increase the repetition frequency and the transition times the electrode can be divided into several smaller capacitive elements. A similar C-type chopper has already been studied like the RAL-ESS "slow chopper" project [6], which consists of a vacuum box with discrete electrodes, each attached to a vacuum feed-through (ceramic insulators) and driven by own "slow pulse generator" (SPG). In these devices the handled power depends on the total effective capacitance (chopper, connections, switch ...). Assuming a total capacitance of $100 \mathrm{pF}$, a $2.5 \mathrm{kV}$ high voltage and the notations of Figure 1 and in Table 1, the power consumption is estimated up to $11.2 \mathrm{~kW}$ in our case. The RAL SPG can provide a $6 \mathrm{kV}$ high voltage, 15 -ns transition time pulse with duration from $100 \mathrm{~ns}$ to $100 \mu \mathrm{s}$, within pulse repetition frequency limited at $1.3 \mathrm{MHz}$. Although RAL SPG seems to be optimistic for our cases, some power studies have to be done to estimate the feasibility and to reach our requirements.

\section{Association of TW Line and static B-field}

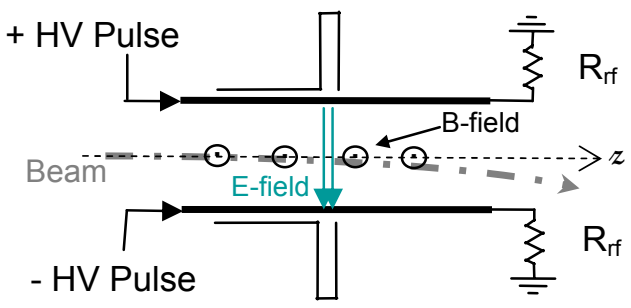

Figure 3: Scheme of the association of a TW mircrotrip line and a static B-field steerer.

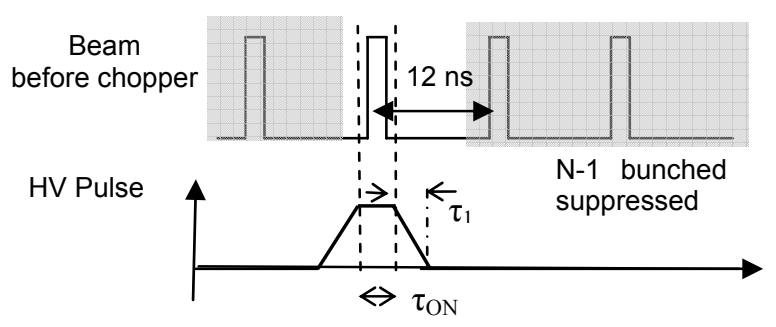

Figure 4: high voltage pulse with inverted duty cycle.
We propose to invert the duty cycle by means of a static B-field steerer (see Fig. 3): bunches are always deflected. The electromagnetic (EM) pulse, provided by two opposite electrodes fed by high voltages of different sign, should cancel the previous deflection effect: thus the EM pulse should let pass one single bunch through the chopper. The pulse duration falls to $7 \mathrm{~ns}$ instead of $96 \mathrm{~ns}$ (see Fig. 4).

Table 2: New specifications of the HV pulse and estimated power performances.

\begin{tabular}{|l|c|c|}
\hline & EURISOL & SPIRAL2 \\
\hline Electrode width & $73 \mathrm{~mm}$ & $64 \mathrm{~mm}$ \\
\hline Duty Cycle & $<10 \%$ & $<1 \%$ \\
\hline High voltage $\left(\mathrm{V}_{0}\right)$ & $< \pm 2.5 \mathrm{kV}$ & $< \pm 2 \mathrm{kV}$ \\
\hline Rise / fall time $\left(\tau_{1}\right)$ & \multicolumn{2}{|c|}{$6 \mathrm{~ns}$} \\
\hline Pulse duration $\left(\tau_{\mathrm{ON}}\right)$ & \multicolumn{2}{|c|}{$7 \mathrm{~ns}$} \\
\hline RF power & $<11.45 \mathrm{~kW}$ & $<1.14 \mathrm{~kW}$ \\
\hline Power losses $\left(\mathrm{R}_{\mathrm{J}}=2.35 \Omega\right)$ & $<622 \mathrm{~W}$ & $<62 \mathrm{~W}$ \\
\hline
\end{tabular}

Preliminary studies have been devoted to adapt the SPL structure for EURISOL and SPIRAL2 cases. Due to the different particle velocities, calculi and 3D EM simulations give an electrode broader in the first case (see Tab. 2). We expect RF powers and power loss respectively up to $11.45 \mathrm{~kW}$ and $622 \mathrm{~W}$ at a $10 \% \mathrm{DC}$. In the SPIRAL2 case, the SPL electrode type seems compatible with the insertion inside a steerer and with the $100 \mathrm{~W}$ limit of heat power which can be dissipated by a ceramic plate. However we exceed this limit in the EURISOL case.

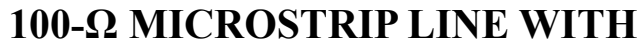 INVERTED DUTY CYCLE}

\section{Design \& Studies}

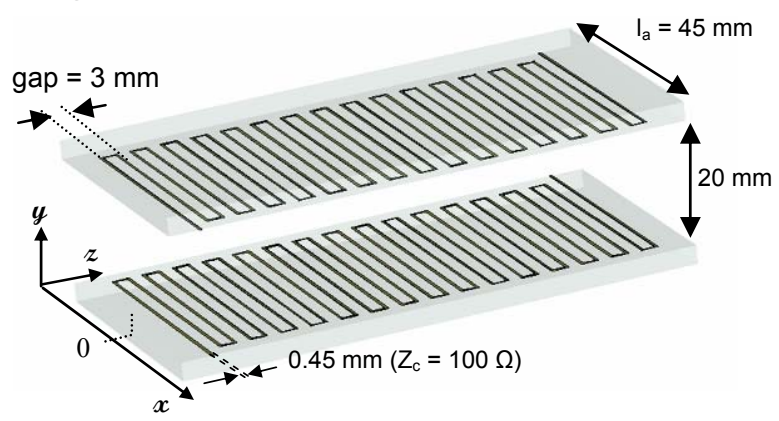

Figure 5: Design of the $100-\Omega$ meander line.

To reduce power consumption and power losses, we decided to investigate a new travelling wave chopper, shown in Figure 5, based on a $100-\Omega$ meander line. The conductor strip is deposited on a ceramic plate $\left(\varepsilon_{\mathrm{r}}=9.6\right)$. After having studied a few values of the gap, a 3-mm gap seems to be a good compromise satisfying the insertion inside a steerer and the beam dynamic requirements. The electrode width is $45 \mathrm{~mm}$ and the coverage factor $74 \%$. By means of 3D EM simulations with Microwave Studio ${ }^{\circledR}$ 
of CST, the variations in the coverage factor as a function of transverse position are shown in figure 6 for three different values of the gap. One observes a $27 \mathrm{~mm}$ width of the field uniformity where the vertical deflecting E-field is always higher than $97 \%$ of its maximum value.

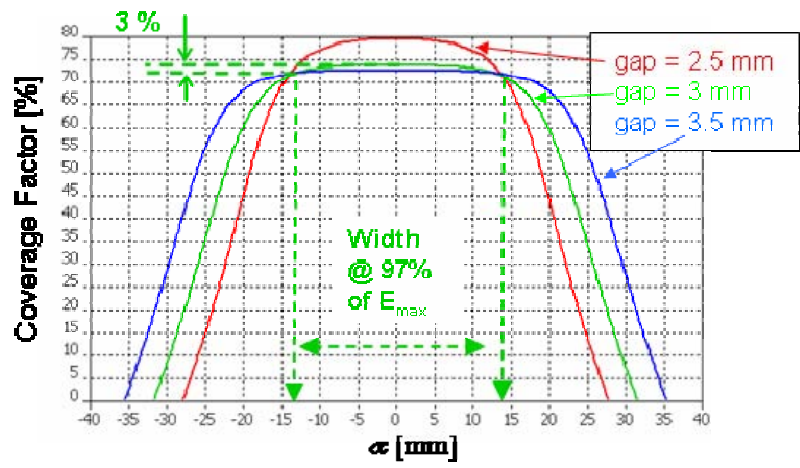

Figure 6: Transverse coverage factor on the beam path.

\section{Comparisons}

Assuming a $2.5 \mathrm{kV}$ high voltage and a $10 \% \mathrm{DC}$, the RF power falls to $5.63 \mathrm{~kW}$ in the $100-\Omega$ meander line instead of $11.45 \mathrm{~kW}$ in the $50-\Omega$ SPL line. The conductor resistances are estimated respectively around of $7.35 \Omega$ and $2.87 \Omega$, which imply respectively power losses lower than $386 \mathrm{~W}$ and $622 \mathrm{~W}$. If we limit the power loss to the value $(100 \mathrm{~W})$ which can be dissipated by a ceramic plate, we gain $30 \%$ on the high voltage $(1.26 \mathrm{kV}$ instead $0.94 \mathrm{kV})$ and on the RF power $(1.46 \mathrm{~kW}$ instead $1.74 \mathrm{~kW})$. Furthermore the $100-\Omega$ electrode width of $45 \mathrm{~mm}$ is more interesting for the insertion inside a steerer than the $73 \mathrm{~mm}$ SPL line adapted to EURISOL. The $27 \mathrm{~mm}$ width of the E-field uniformity, described on the figure 6 , is better than the $20 \mathrm{~mm}$ width, obtained by a SPL double meander line adapted to EURISOL.

\section{Pulse propagation}

Since the ideal pulse plotted in Figure 4 is a periodic function, one can decompose it into a Fourier series. For any duty cycle the theoretical high harmonic is $440 \mathrm{MHz}$ if a voltage gap $<40 \mathrm{~V}(<2 \%)$ is accepted. A microstrip line has a group velocity and an attenuation which depend on the frequency and which lead to pulse shape distortion for long structures. 3D EM simulations of a short $100-\Omega$ meander line at the frequency range up to $440 \mathrm{MHz}$ show a good transmission and a good matching. Then the phase of $\mathrm{S}_{21}$ depends on the velocity to the minus one. Thereafter the delay time of each harmonic may be deduced from the velocity and be implemented in the Fourier series. The attenuation due to the conductor loss has to be taken into account too for the harmonic magnitude calculation. In figure 7 are plotted the input and output pulses versus time in a $7.297 \mathrm{~m}$ microstrip line, equivalent to a $450 \mathrm{~mm}$ long electrode. The maximum variation is close to $300 \mathrm{~V}(<12 \%)$. Due to this variation and the fringe field effects, the static B-field could not be perfectly cancelled by the EM pulse. Consequently partially beam would be deflected instead of passing through the chopper.

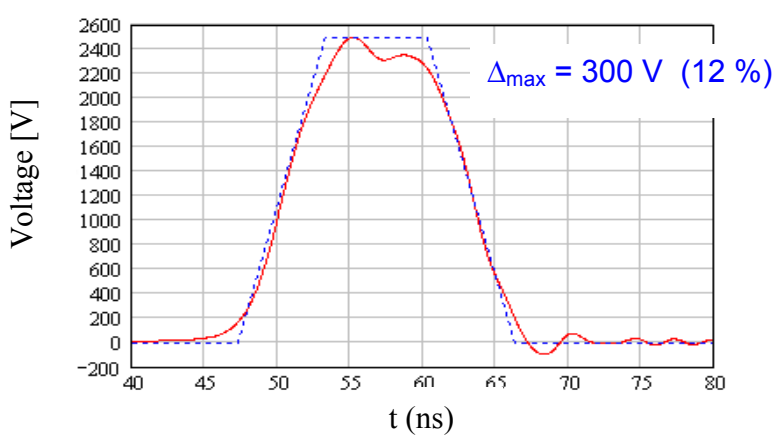

Figure 7: Comparisons between input (dot) and output (solid) pulse of a $7.297 \mathrm{~m}$ long microstrip line.

\section{CONCLUSION}

Association of a static B-field steerer with a TW chopper is essential to invert DC. A SPL $50-\Omega$ electrode seems to be adapted for SPIRAL2. To reach $10 \%$ DC, a $100-\Omega$ line electrode is the first step but there remains still much work to reach $2.5 \mathrm{kV}$. From a review of existing generators [5], requirements for the chopper are at the border of the existing structures: one can expect a maximum $2 \mathrm{kV}$ high voltage within $7 \mathrm{~ns}$ rise-time and a $1 \% \mathrm{DC}$ (from $[3,4]$ ). At this day we wait for answers of commercial factories about feasibilities for pulse generators. Furthermore studies must be done to decrease the frequency bandwidth of the generator by modifying the pulse shape. Electrodes prototypes of the EURISOL and SPIRAL2 choppers are foreseen to be developed in a near future.

\section{ACKNOWLEDGEMENTS}

We acknowledge F. Caspers, T. Kroyer, A. Lombardi and M. Paoluzzi at CERN, as well as M. Clarke-Gayther at RAL for their help and their information.

\section{REFERENCES}

[1] T. Kroyer, F. Caspers and E. Mahner, "The CERN SPL Chopper Structure, A Status Report", CAREReport-06-033-HIPPI, CERN, Januar 10 ${ }^{\text {th }}, 2007$.

[2] F. Caspers, Y. Cuvet, J. Genest, M. Haase, M. Paoluzzi and A. Teixeira, "The CERN-SPL Chopper Concept and Final Layout", EPAC'04, Lucerne, July 2004, p. 1141.

[3] M. Clarke-Gayther, "Fast-Slow Beam Chopping for Next Generation High Power Proton Drivers", PAC'05, Knoxville, May 2005, p. 3635.

[4] R. Hardekopf, S. Kurennoy, J. Power, R. Roybal, D. Scharge, R. Sherwood and S. Collins, "Fabrication of the MEBT Chopper System for the Spallation Neutron Source”, PAC'03, Portland, May 2003, p. 1661.

[5] G. Le Dem, "High Frequency Chopper of the HeavyIon Accelerator - Annual Status Report", April, 2007, http://www.eurisol.org/site01/doc_details.php? EURpub $=1 \& \mathrm{dID}=757 \& \mathrm{tID}=10$.

[6] M. Clarke-Gayther, "Beam Chopper R\&D for Next Generation High Proton Drivers", HIPPI'06 general meeting, Geneva, May 2006. 